\title{
COMPOSIÇÃO QUÍMICA E DEGRADABILIDADE in situ DA MATÉRIA SECA DE LEGUMINOSAS NO SEMI-ÁRIDO BAIANO
}

\section{Chemical composition and dry matter in situ degradability of arboreal legumes from Brazilian Semi-Arid region}

\author{
SANTOS, E.M. ${ }^{1}$; ZANINE, A.M. ${ }^{2}$; FERREIRA, D.J. ${ }^{3}$; OLIVEIRA, J.S. ${ }^{1}$; PEREIRA, O.G. ${ }^{3}$; \\ CECON, P.R. ${ }^{3}$; EDVAN, R.L. ${ }^{1}$; VASCONCELOS, W.A. ${ }^{4}$
}

1 Universidade Federal da Paraíba

2 Universidade Federal de Mato Grosso

3 Universidade Federal de Viçosa

${ }^{4}$ Instituto Nacional do Semi-Árido

Endereço para correspondência: Ricardo Loiola Edvan: agroloiola@hotmail.com

\section{RESUMO}

$\mathrm{Na}$ tentativa de prover alternativas para a instabilidade climática da região semi-árida brasileira foi realizado um experimento para avaliar a composição bromatológica e a degradabilidade in situ da matéria seca de leguminosas arbóreas no semi-árido baiano. As leguminosas avaliadas foram Muquem (Albizia polyantha), Tamboril (Enterolobium contortisiliquum) e Leucena (Leucaena leucocephala). Foram coletadas amostras em três florestas do município de Bom Jesus da Lapa, no estado da Bahia, uma amostra composta em cada floresta. Determinaram-se os teores de matéria seca, proteína bruta, fibra em detergente neutro, fibra em detergente ácido, hemicelulose, matéria orgânica, material mineral e a degradabilidade in situ da matéria seca. As plantas estudadas apresentaram em torno de $45 \%$ de matéria seca. O teor de proteína bruta das leguminosas Muquem e Leucena, apesar da diferença estatística, foram muito próximos (17,0\%). Houve diferença para a qualidade das fibras sendo o menor valor de fibra em detergente neutro observado para a Leucena, seguido do Muquem e Tamboril. A Leucena, durante todo o período de incubação, apresentou maior digestibilidade ruminal seguido do Muquem e do Tamboril. Pode-se concluir que, apesar da superioridade da Leucena, a leguminosa Tamboril, bem como o Muquem, podem ser alternativas para a alimentação de bovinos no ecossistema caatinga.

Palavras-chave: Albizia polyantha; Enterolobium contortisiliquum; Leucaena leucocephala

\section{ABSTRACT}

To offer alternatives for the climatic instability of the Brazilian semi-arid an experiment was accomplished to evaluate the bromatologic composition and the dry matter in situ degradability of arboreal legumes from brazilian semi-arid. The appraised legumes were Muquem (Albizia polyantha), Tamboril (Enterolobium contortisiliquum) and Leucena (Leucaena leucocephala). Samples were collected at three forests of the municipal district of Bom Jesus da Lapa, in the Bahia state, a sample composed in each forest. There were determined the dry matter content, crude protein, detergent neutral fiber, acid detergent fiber, hemicelulose, organic matter, mineral matter and dry matter in situ degradability. The studied legumes presented $45 \%$ around of dry matter. The crude protein content of the Muquem legume and Leucena in spite of the statistical difference were very close $(17.00 \%)$. there was difference for the quality of the fibers with the smallest detergent neutral fiber value observed for the Leucena, following by the Muquem and Tamboril. The Leucena, during the whole incubation period, presented larger digestibilidade ruminal following by the Muquem and of the Tamboril. We can conclude that in spite of the superiority of the Leucena the leguminosa Tamboril and Muquem can be alternative for the feeding of the flock in the ecosystem of Savanna.

Key words: Albizia polyantha; Enterolobium contortisiliquum; Leucaena leucocephala 


\section{INTRODUÇÃO}

A produção animal na região do nordeste do Brasil encontra barreiras para o seu desenvolvimento devido às adversidades climáticas. $\mathrm{Na}$ estação seca, as altas temperaturas e baixos índices pluviométricos durante o ano são características dos climas áridos e semi-áridos, e prejudicam a produção de alimentos para os rebanhos (STEIN, 2002). Por isso, os pecuaristas nordestinos enfrentam grandes dificuldades para manter seus rebanhos, principalmente, na estiagem, onde a suplementação dos animais é de suma importância para a sobrevivência dos mesmos.

As leguminosas arbóreas e arbustivas são fontes alternativas e baratas de proteína para a produção animal, podendo também melhorar a fertilidade do solo, proporcionar sombra, servir de cobertura do solo e como fonte de lenha para uso doméstico. Elas oferecem vantagens sobre muitas espécies herbáceas em termos de persistência, enraizamento profundo, resistência a manejo inadequado e na habilidade de reter forragem de alta qualidade em épocas desfavoráveis (Gutteridge, 1990; Argel e Maass, 1995).

Devido a esses fatores, a utilização de alimentos alternativos que sejam adaptados às intempéries dessa região hostil, $\mathrm{e}$ que são fontes de nutrientes de baixo custo, pode ser uma alternativa interessante para a sustentabilidade da produção animal neste ecossistema. Dentro dessa lógica, as leguminosas arbóreas nativas do nordeste brasileiro poderiam suprir as carências protéicas e energéticas dos animais. Muitas dessas espécies apresentam elevado valor de proteína bruta, sendo abundantes nas épocas chuvosas, e com elevado potencial para produção de feno (Nozella, 2001; Longo, 2002).

A degradabilidade da matéria seca é uma função do tempo, quando se usam fermentações in vivo ou in situ. Em sua maioria, estes dados adaptam-se a um modelo geral com três variáveis: "a" é a matéria seca que é rapidamente degradada; "b" é a matéria seca potencialmente degradável e "c" é a taxa de degradabilidade da fração "c" (Malafaia, 1997).

São necessários estudos mais criteriosos sobre a disponibilidade de nutrientes de leguminosas arbóreas que estão evolutivamente presentes no ecossistema da caatinga como o Muquem e o Tamboril, determinando sua provável contribuição para a nutrição animal. Assim, o presente trabalho objetivou avaliar a composição bromatológica e a cinética de degradação ruminal por meio da degradabilidade in situ potencial e efetiva da matéria seca de leguminosas arbóreas do semi-árido baiano.

\section{MATERIAL E MÉTODOS}

O experimento foi realizado nas instalações do Setor de Bovinocultura de Leite da Universidade Federal de Viçosa, em Viçosa, Minas Gerais. Foram utilizados três bovinos machos, castrados, fistulados no rúmen, com peso vivo médio de $400 \mathrm{~kg}$. Os animais receberam diariamente silagem de sorgo e concentrado a base de milho e farelo de soja na proporção 60:40. Foram avaliadas três plantas arbóreas presentes no semi-árido baiano: Muquem (Albizia polyantha), Tamboril (Enterolobium contortisiliquum) e a Leucena (Leucaena leucocephala), coletadas no município de Bom Jesus da Lapa, localizado no estado da Bahia, no nordeste brasileiro, latitude

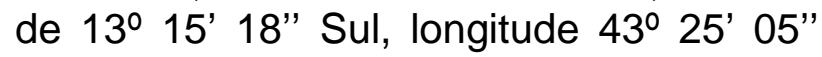
Oeste. O período chuvoso é de outubro a fevereiro com precipitação média, nos últimos cinco anos, de $700 \mathrm{~mm}$. Foram coletadas 10 amostras simples de cada espécies, que ocorriam naturalmente nas áreas de caatinga estudadas, que formaram uma amostra composta utilizada nas avaliações. As plantas foram coletadas em três localidades diferentes, manualmente, quando as mesmas se encontravam em vegetação plena (verão, 
mês de janeiro). Foram colhidas somente as folhas e ramos de cada planta. Não foram considerados na avaliação altura da planta e estádio vegetativo, pois optou-se pela coleta da material das plantas de ocorrência natural, sendo que o único aspecto considerado foi a época de maior concentração de chuvas naquela região. Os parâmetros avaliados foram, matéria seca (MS), proteína bruta (PB), fibra em detergente neutro (FDN), fibra em detergente ácido (FDA), hemicelulose $(\mathrm{HM})$, cinzas (CZ), matéria orgânica (MO) e a degradabilidade in situ da matéria seca (DISMS). O teor de MS foi determinado em estufa de $65^{\circ} \mathrm{C}$ até o peso constante e, após, levou-se a uma estufa a $105^{\circ} \mathrm{C}$ para se obter o teor de matéria seca definitiva. $O$ valor de $\mathrm{PB}$ foi determinado pelo método de Kjeldahl. Os teores de FDN e FDA foram determinadas pelo método de Van Soest (1999). As cinzas foram determinadas na mufla à temperatura de $550^{\circ} \mathrm{C}$, sendo a matéria orgânica extraída por diferença entre os valores de matéria seca e cinzas.

A estimativa de degradabilidade ruminal da matéria seca dessas plantas foi estimada por meio da técnica in situ com saco de náilon. Em cada saco foram colocados $3 \mathrm{~g}$ de amostras dessas espécies. Nos dias de incubação, cada amostra foi atada a uma corrente de ferro introduzida no rúmen via fistula ruminal, fixa por um fio de náilon de $60 \mathrm{~cm}$ de comprimento. Os tempos de incubação foram $0,6,12,18,24,48,72$ e 96 horas. Foram utilizados três saquinhos por animal por tempo. Após a remoção dos sacos do rúmen, estes foram lavados em água corrente e, posteriormente, foram submetidos à secagem em estufa com ventilação forçada a $65^{\circ} \mathrm{C}$, por 72 horas. As amostras do tempo 0 também sofreram o mesmo processo de lavagem e secagem. Do que restou das amostras nos sacos, após a incubação ruminal, foi obtido o teor de matéria seca, em estufa de ventilação forçada a $105^{\circ} \mathrm{C}$ por 72 horas. $\mathrm{A}$ degradabilidade potencial (DP) da matéria seca foi calculada por meio da equação descrita por Mehrez e Orskov (1977). As degradabilidades efetivas (DE) da matéria seca foram estimadas para $2 \% / \mathrm{h}, 5 \% / \mathrm{h}$, $8 \% / h$ de taxas de passagem de sólidos. A equação utilizada para estimar degradabilidade efetiva foi descrita por Orskov e McDonald (1979).

Os dados foram submetidos à análise de variância e os valores médios dos constituintes bromatológicos das leguminosas foram comparados pelo teste de Tukey a $5 \%$ de probabilidade. Os parâmetros não lineares da fração solúvel ("a"), potencial de degradação ("b"), e taxa de degradação ("c") foram estimadas pelos procedimentos interativos de quadrados mínimos utilizando-se o programa SAEG versões 8.0 (Universidade Federal de Viçosa-UFV, 1999).

\section{RESULTADOS}

$\mathrm{Na}$ Tabela 1, podem ser observados os valores da composição bromatológica das leguminosas estudadas. Houve diferença estatística $(\mathrm{P}<0,05)$ para os valores nutricionais das leguminosas, com exceção dos valores de $M S$, que não apresentaram diferenças $(P>0,05)$, ficando com valores médios em torno de $47 \%$.

Para os valores de PB foram observadas diferenças $(P<0,05)$ entre as leguminosas, ficando o Muquem apesar da diferença estatística, com valor de PB, muito próximo ao valor da Leucena. $O$ menor valor de PB foi observado para o Tamboril.

Houve diferenças Com relação aos valores da FDN e FDA, estatísticas $(P<0,05)$ entre as leguminosas e uma similaridade em relação a essas duas fibras.

Com relação ao material mineral ou cinzas, o menor valor foi observado para o Muquem (4,1\%) não havendo diferenças estatísticas $(P>0,05)$ para o Tamboril e a 
Tabela 1 - Teores de matéria seca (MS), proteína bruta (PB), fibra em detergente neutro (FDN), fibra em detergente ácido (FDA), hemicelulose (HEM), cinzas (CZ) e matéria orgânica (MO) de leguminosas arbóreas

\begin{tabular}{lccccccc}
\hline Leguminosa & $M S$ & $P B$ & $F D N$ & $F D A$ & $H E M$ & $C Z$ & $M O$ \\
\hline Muquem & $43,7 \mathrm{a}$ & $17,1 \mathrm{~b}$ & $69,7 \mathrm{~b}$ & $41,8 \mathrm{~b}$ & $27,9 \mathrm{a}$ & $4,1 \mathrm{~b}$ & $95,9 \mathrm{~b}$ \\
Tamboril & $50,0 \mathrm{a}$ & $14,0 \mathrm{c}$ & $84,1 \mathrm{a}$ & $70,3 \mathrm{a}$ & $13,7 \mathrm{~b}$ & $5,6 \mathrm{a}$ & $94,4 \mathrm{~b}$ \\
Leucena & $45,7 \mathrm{a}$ & $18,4 \mathrm{a}$ & $30,7 \mathrm{c}$ & $14,3 \mathrm{c}$ & $16,1 \mathrm{~b}$ & $6,2 \mathrm{a}$ & $93,8 \mathrm{a}$ \\
\hline CV(\%) & 7,67 & 2,79 & 1,76 & 2,26 & 8,82 & 6,76 & 7,67 \\
\hline
\end{tabular}

Médias seguidas de mesma letra na coluna não diferem estatisticamente pelo teste de Tukey ao nível de $5 \%$ de probabilidade

Tabela 2 - Frações solúveis (a), potencialmente degradáveis (b) e taxa de degradação (c)

\begin{tabular}{lcccc}
\hline Plantas & $\mathrm{a}$ & $\mathrm{b}$ & $\mathrm{c}(\% / \mathrm{h})$ & $\mathrm{R}^{2}$ \\
\hline Muquem & 1,96 & 34,1 & 9,5 & 0,938 \\
Tamboril & 2,97 & 35,0 & 3,0 & 0,976 \\
Leucena & 8,16 & 70,0 & 7,0 & 0,991 \\
\hline
\end{tabular}

leucena. Para a matéria orgânica o maior valor $(93,8 \%)$, foi observado para a leucena, não havendo difernças estatísticas $(P>0,05)$ entre o Muquem e o Tamboril.

$\mathrm{Na}$ Tabela 2 podem ser observados os valores das frações "a", "b" e a taxa de degradação da fração "c" da matéria seca das espécies arbóreas estudadas.

Observou-se que a Leucena foi, entre as plantas, a que conteve os maiores valores de fração rapidamente solúvel ("a"), sendo que as outras plantas tiveram a fração "a", que é prontamente disponível para fermentação, bem aquém da Leucena. Essa fração foi quatro vezes menores no Muquem e três vezes menores no Tamboril, em relação a Leucena. Essa mesma resposta foi observada na fração insolúvel, mas potencialmente degradável ("b"), em que a Leucena apresentou duas vezes mais essa fração que as outras plantas. O Muquem foi o que apresentou os menores valores da fração solúvel ("a") e insolúvel, mas potencialmente degradável ("b"). O Tamboril apresentou valores intermediários tanto para fração solúvel quanto para fração insolúvel, mas potencialmente degradável. A superioridade da Leucena pode ser visualizada claramente na Figura 1 , onde estão às curvas e respectivas equações de regressão das três espécies arbóreas para degradabilidade potencial.

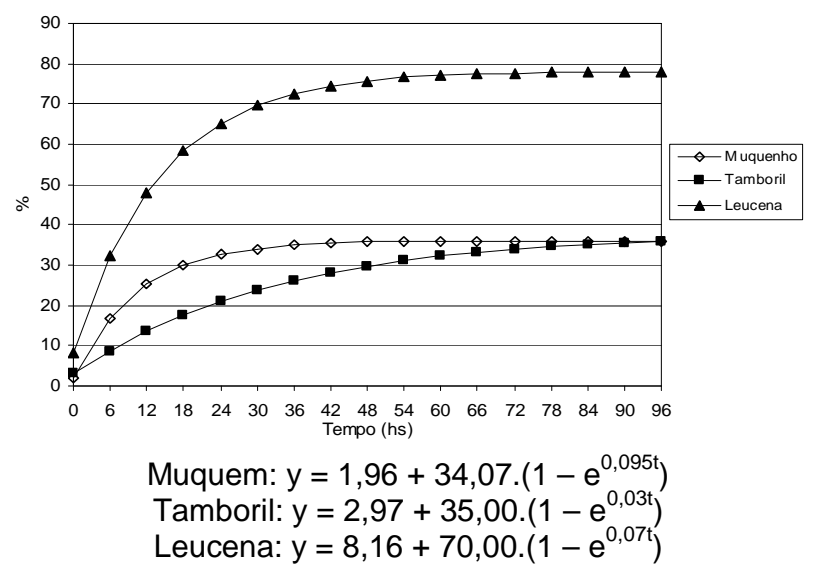

Figura 1 - Degradabilidade potencial da matéria seca das espécies arbóreas.

A Leucena, durante todo o período de incubação, apresentou maior digestibilidade ruminal quando comparada às outras plantas $(P<0,01)$. Este mesmo comportamento se repete na degradabilidade efetiva onde a Leucena, nas três taxas de passagem $(2 \%, 5 \%$ e $8 \% / h)$, foi superior aos demais, com, respectivamente, $62,6 \%$, 
$49,0 \%$ e $40,8 \%$ de degradabilidade efetiva da MS nas diferentes taxas de passagem.

\section{DISCUSSÃO}

Os valores encontrados para matéria seca (Tabela 1) estão próximos aos observados por Zanine et al. (2005) nas leguminosas Vaqueta (Aspidosperma cuspa Kunth) (54\%) e Pau rato (Caesalpinia pyramidalis) (37\%) da mesma região avaliada no presente trabalho, leguminosas estas também arbóreas e pertencentes ao ecossistema da caatinga Baiana. Nozella (2001), avaliando as leguminosas arbóreas Angico (Anadenanthera macrocarpa), Gliricídia (Gliricídia sepium), Leucena (Leucena leucocephala) e Jurema, relatou valores de MS na ordem de 54, 21, 29 e 42\%, respectivamente. Note que o valor da MS descrito pelo autor para a Leucena é inferior ao observado no presente trabalho.

Os valores de PB para Leucena foram inferiores aos observados por Rodriguez et al. (1996), que relataram valores de 25,0 para a Leucena. Os valores de PB da leguminosa Muquem e da Leucena estão próximos dos descritos por Nozella (2001), para as leguminosas Angico, Gliricídia, Leucena e Jurema que foram: 16, 20, 21, $37,17,6$ e $16 \%$, respectivamente. Pereira Filho et al. (2003), trabalhando com a Jurema Preta, observaram um valor de PB de $14,4 \%$, valor este semelhante ao verificado para o Tamboril no presente experimento. Isto sugere que leguminosas de ocorrência natural apresentam potencial como fontes de proteína para animais, podendo ser utilizadas tanto quanto espécies introduzidas no semi-árido, como a Leucena. Zanine et al. (2005), observaram também valores elevados de PB para as leguminosas Vaqueta, Jurema e Pau rato, de 13, 14,5 e 19,7\%, respectivamente.

Para FDN e FDA o Muquem e a Leucena apresentaram os menores valores e o Tamboril o maior valor, sendo o maior valor de HEM encontrado no Muquem. Silva et al. (2004), observaram valores de 15,6 e $41,8 \%$ de FDA, na Leucena e no Desmodium ovalifolium, respectivamente. Já Rodriguez et al. (1996) observaram valores de 37,1 e $58,2 \%$ para a FDN e 13,4 e 41,9 para a FDA, para a Leucena e o Guandu, respectivamente. Nozella (2001) descreveu valores de FDN e FDA, para o Angico, Gliricídia e Leucena, na ordem de $40,4,31,8$ e $21,9 \%$, para a FDN e 29,9 , 31,9 e $21,9 \%$, para a FDA, respectivamente.

Nozella (2001) relatou que Angico, Gliricídia e Leucena, apresentaram valores de material mineral na ordem de 4,3, 4,9 e $6,2 \%$, respectivamente, sendo esses valores próximos aos observados para 0 Muquem e o Tamboril.

A degradabilidade da matéria seca encontrada neste experimento se assemelha ao obtido por Longo (2002), que verificou em seu estudo o coeficiente de digestibilidade da matéria seca da Leucena em torno de 53\%. O Muquem apesar de menores valores na fração "a" e "b", apresentou a maior taxa de degradação ("c") da fração "b" da MS, com isso, ao longo do tempo, esta planta foi fermentada mais rapidamente que 0 Tamboril. Este mesmo resultado foi observado para a digestibilidade efetiva.

Nas três taxas de passagem, o Muquem foi superior ao Tamboril, com degradabilidade efetiva da MS de $30,1 \%$, $24,3 \%$ e $20,5 \%$, em comparação ao Tamboril com degradabilidade efetiva da MS de $24,0 \%, 16,1 \%$ e $12,5 \%$, nas três taxas de passagem. Rodriguez et al. (1996), avaliando a degradabilidade dos folíolos de leguminosas arbóreas, observaram que a leguminosa Leucena teve valores da fração "a", "b" e "c", na ordem de 15,3, 93,2 e 6,9\%, respectivamente, ficando próximos aos valores observados no presente experimento. Para o Guandu (Cajanus cajan (L.) Millsp.) os autores observaram 
degradabilidade ruminal, na ordem de 7,2 e 1,6\% nas frações "a" e "c". Quando se compara à fração "c" do Guandu (1,60\%), as leguminosas do presente experimento obtiveram maiores valores, 9,5 e 3,0\% para o Muquem e o Tamboril. Nozella (2001), estudando as leguminosas arbóreas Leucena, Gliricídia, Angico, Jurema e Guandu, observou valores para a fração "a" e "b" na ordem de 39,1, 31,4, $17,6,25,2$ e $23,9 \%$ e $79,1,72,3,37,0,75,5$ e 58,0\%, respectivamente. Martinez e Thomazini (1996), avaliando a degradabilidade da matéria seca da Leucena observaram valores de $42,8 \%$. No entanto, não foram encontrados na literatura dados referentes ao Muquem e Tamboril.

Informações referentes aos métodos de plantio, escarificação de sementes e produção de mudas da leguminosa Tamboril foram descritas por Alcalay e Amaral (1982), Eira et al. (1993), Mattei (1996), Barberi et al. (1998), Tokarnia et al. (2000), Malavasi et al. (2004) e Meneghello e Mattei (2004). Desta forma, esta leguminosa poderia ser amplamente explorada, com base nas informações já disponíveis na literatura.

\section{CONCLUSÕES}

As leguminosas do estrato arbóreo do semi-árido apresentaram altos teores de proteína bruta e moderados valores de fibra, sendo que a Leucena é degradada mais eficiente no rúmen dos animais.

\section{REFERÊNCIAS}

ALCALAY, N.; AMARAL, D.M.I. Quebra de dormência em sementes de timbaúba Enterolobium contortisiliquum (Vell.) Morong. Silvicultura em São Paulo, n.16, v.1159-1162, 1982.

ARGEL, P.J.; MAASS, B. Evaluación y adaptación de leguminosas arbustivas em suelos ácidos infertiles de América tropical. In: EVANS, D.O.; SZOTT, L.T. (eds.). Nitrogen Fixing Trees for
Acid Soils, Turrialba,1995. Nitrogen Fixing Tree Research Reports Special Issue, p.215-227, 1995.

BARBERI, A.; CARNEIRO, M.A.C.; MOREIRA, F.M.S. ET AL. Nodulação em leguminosas florestais em viveiros no sul de Minas Gerais. CERNE, v 4, n.1, p.145-153, 1998.

EIRA, M.T.S.; FREITAS, R.W.A.; MELLO, C.M.C. Superação da dormência de sementes de Enterolobium contortisiliquum (Vell.) Morong. Leguminosae. Revista Brasileira de Sementes, n.15, v.2, p.177-181, 1993.

GUTTERIDGE, R.C. Agronomic evaluation of tree and shrub species in southeast Quensland. Tropical Grasslands, v.24, n.1, p.29-34, 1990.

LONGO, C. Avaliação do uso de Leucaena leucocephala em dietas de ovinos da raça Santa Inês sobre o consumo, a digestibilidade e a retenção de nitrogênio. 2002. 49f. (Mestrado em Agronomia), Universidade de São Paulo, Piracicaba, 2002.

MALAFAIA, P.A.M. Taxas de digestão das frações protéicas e de carboidratos de alimentos por técnicas "in situ", "in vitro" e de produção de gases. 1997. 85f. (Doutorado em Zootecnia) - Universidade Federal de Viçosa, Viçosa, 1997.

MALAVASI, U.C.; MALAVASI, M.M. Dormancy breaking and germination of

Enterolobiumcontortisiliquum (Vell.) morong seed. Brazilian Archives of Biology and technology, n.6, v.47, 2004.

MARTINEZ, J.L.; THOMAZINI, P.L. Uso da Uréia ou da Leucena na Engorda de Bubalinos em Confinamento no Litoral do Paraná. In: REUNIÃO ANUAL DA SOCIEDADE BRASILEIRA DE ZOOTECNIA, 33., Fortaleza. Anais...

Fortaleza:SBZ. 1996. (CDROM).

MATTEI, V.L. Semeadura de Timbaúva (Enterolobium contortisiliquum (Vell.) Morong), diretamente no campo no enriquecimento de capoeiras In: SEMINÁRIO PANAMERICANO DE SEMILLAS, 15., 1996, Gramado. Anais... Gramado: FELAS, p.90, 1996.

MEHREZ, A.S.; ORSKOV, E.R. A study of artificial fiber bag technique for determining the digestibility of feeds in the rumen. Journal Agricutural Science, v.88, p. 645-650, 1977.

MENEGHELLO, G.E.; MATTEI, V.L. Semeadura direta de Timbauva (Enterolobium contortisiliquum), canafístula (Peltophorum dubium) e cedro (Cedrela fissilis), em campos abandonados. Ciência

Florestal, v.14, n.2, p.21-27, 2004.

NOZELLA, E.F. Determinação de tanino em plantas com potencial forrageiro para 
ruminantes. 2001. 58f. (Mestrado em Agronomia). Universidade de São Paulo, Piracicaba, 2001.

ORSKOV, E.R.; McDONALD, I. The estimation of protein degradability in the rúmen from incubation measurements weighted according to rate of passage. Journal Agricutural Science, v.92, n.1, p.499-503, 1979.

PEREIRA FILHO, J.M. ; VIEIRA, E.L. ; SILVA, A.M.A. et al. Efeito do tratamento com hidróxido de sódio sobre a fração fibrosa, digestibilidade e tanino do feno de jurema-preta (Mimosa tenuiflora. Wild).

Revista Brasileira Zootecnia. v.32, p.70-76, 2003.

RODRIGUEZ, N.M.; VELOSO, C.M.; MOURÃO, G.B. et al. Degradabilidade ruminal de proteína de folíolos de Leucena, guandu e soja perene e de folhas de rami e mandioca. In: REUNIÃO ANUAL DA SOCIEDADE BRASILEIRA DE ZOOTECNIA, 33., Fortaleza. Anais... Fortaleza:SBZ, 1996. (CDROM).

SILVA, M.M.C; GUIM A.; PIMENTA FILHO, E.C. et al. Avaliação do padrão de fermentação de silagens elaboradas com espécies forrageiras do estrato herbáceo da caatinga nordestina. Revista

Brasileira de Zootecnia, v.33, n.1, p.87-96, 2004.
STEIN, R.B.S. Avaliação de métodos para determinação da digestibilidade aparente utilizando farelo de vargem de algaroba (Prosopis Juliflora (SWARTZ) D.C.) em eqüinos. 2002. 86f. (Mestrado em Zootecnia). Universidade de são Paulo, Pirassununga, 2002.

TOKARNIA, C.H.; DÖBEREINER, J.; PEIXOTO, P.V. Plantas tóxicas do Brasil. Rio de Janeiro: Ed. Helianthus, 2000, 310p.

UFV-UNIVERSIDADE FEDERAL DE VIÇOSA. S.A.E.G. (Sistemas de Análises Estatísticas e Genéticas). Viçosa: MG (Versão 8.1), p. 138, 1999.

VAN SOEST, P.J. Nutritional ecology of the ruminant. 2. ed. Cornell University Press, 1999. $476 p$.

ZANINE, A.M.; SANTOS, E.M.; FERREIRA, D.J. et al. Composição bromatológica de leguminosas do semiárido brasileiro. Livestock Research for Rural Development. v.17, p.1-9, 2005. 